Int. J. Dev. Biol. 54: 175-180 (2010)

doi: $10.1387 /$ ijdb. $082610 \mathrm{bl}$

\title{
Signalling molecules involved in mouse bladder smooth muscle cellular differentiation
}

\author{
BENCHUN LIU1', DONGXIAO FENG², GUITING LIN1', MEI CAO1, YUET WAI KAN², \\ GERALD R. CUNHA ${ }^{1}$ and LAURENCE S. BASKIN*,1 \\ ${ }^{1}$ Department of Urology and ${ }^{2}$ Department of Genetics, University of California, San Francisco, \\ San Francisco, CA, USA
}

\begin{abstract}
Mouse bladder mesenchyme differentiates into smooth muscle under the influence of urothelium at gestational day 13.5 (E13.5). Sonic hedgehog (Shh) is considered to be the upstream gene arising from the urothelium, which induces smooth muscle in the peripheral bladder mesenchyme. We hypothesize differential gene expression across the full thickness of bladder mesenchyme as a function of proximity to the inducing bladder urothelium and the peripheral location of the smooth muscle. Embryonic bladders from FVB mice were collected at E12.5, 13.5, 15 and 16 and cryosectioned followed by microdissection with a PixCell@ II laser capture microscope. RNA extraction was performed at the laser captured sites and mRNA expression profiles were measured using SYBR Green quantitative RT-PCR. Smooth muscle $\alpha-$ actin (SMAA) and smooth muscle myosin heavy chain (SM-MHC) were expressed in the E13.5, E15 and E16 bladders in the peripheral layer of mesenchyme, but not in the prospective submucosa. Patched 1 (Ptc1), Gli1 and bone morphogenetic protein (Bmp) 4 expression was consistently elevated in the mesenchymal layer immediately adjacent to the urothelium compared to the peripheral location at E12.5. After E12.5, Ptc1 expression decreased to an undetectable level throughout the bladder mesenchyme. The level of TGF- $\beta 1$ was highest in the mesenchymal layer adjacent to the serosa at E13.5. The level of expression of serum response factor (SRF) was also highest at E15 in the peripheral mesenchyme. Genes downstream of Shh are differentially expressed in the prospective submucosa vs. the peripheral bladder mesenchyme as a function gestation age and smooth muscle differentiation.
\end{abstract}

KEY WORDS: bladder, laser capture microdissection, mesenchyme, signaling, smooth muscle

Reciprocal epithelial-mesenchymal interactions are essential for growth, differentiation, and patterning of many vertebrate organs, including the bladder (Baskin et al., 1996; Liu et al., 2000). Differentiation of smooth muscle in the embryo is temporally and spatially coordinated within the bladder mesenchyme by signals arising from the bladder epithelium (Baskin et al., 1996; Li et al., 2006; Shiroyanagi et al., 2007).

Previous work has shown that an epithelial signal is necessary for the induction of bladder smooth muscle (Baskin et al., 1996; Shiroyanagi et al., 2007), and that the smooth muscle-inducing signal is a diffusible (Liu et al., 2000). The paradox is that smooth muscle develops in the peripheral bladder mesenchyme adjacent to the serosa surface and not in the mesenchyme immediately adjacent to the smooth muscle inducing urothelium. The presumption is that the epithelial signal is transmitted through the submucosal zone (which does not undergo smooth muscle differentiation) to the peripheral bladder mesenchyme. Perhaps the submucosal connective tissue and/or basement membrane of the bladder act as inductive or repressive signaling channels or mediators of smooth muscle differentiation in their own rights (Liu et al., 2000; Chuang et al., 2000).

Insight into bladder smooth muscle differentiation comes from both cellular and genetic studies. Smooth muscle differentiation in the mouse urinary bladder occurs at gestational day 13.5 (E13.5) (Li et al., 2006; Shiroyanagi et al., 2007). cDNA microarray gene expression profiles of intact embryonic murine bladders

Abbreviations used in this paper: LCM, laser capture microdissection; Shh, sonic hedgehog; SMAA, smooth muscle $\alpha$-actin; SM-MHC, smooth muscle myosin heavy chain; SRF, serum response factor.

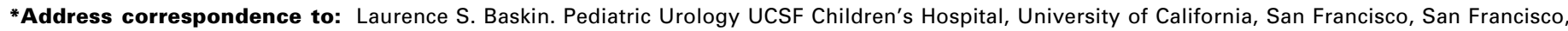

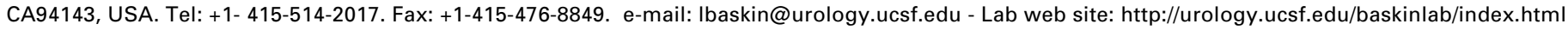


have identified regulators of vascular smooth muscle differentiation in bladder mesenchyme, including serum response factor (SRF) and its cofactors, ELK1 and SRF accessory protein (SAP) 1 , as well as two SRF-associated pathways, angiotension receptor II and transforming growth factor-beta (TGF- $\beta$ ) 2 (Li et al., 2006). These results suggest that bladder smooth muscle differentiation may share a similar gene expression program as occurs during vascular smooth muscle differentiation (Wijgerde et al., 2002; Yu et al., 2002; Kumar and Owens, 2003; Weaver et al., 2003; Owens et al., 2004; Li£ et al., 2006; White et al., 2006; Haraguchi et al., 2007; Jenkins et al., 2007; Morrow et al., 2007; Shiroyanagi et al., 2007).

To analyze differences in gene expression among different cellular populations in the bladder, gene expression before and after smooth muscle differentiation was evaluated using laser capture microdissection (Bonner et al., 1997; Green et al., 2003; Hong et al., 2004; Jacquet et al., 2005; Kerman et al., 2006).

\section{Results}

At E12.5, mRNA of smooth muscle markers, $\alpha$-actin (SMAA) and smooth muscle myosin heavy chain (SM-MHC), were undetectable in bladder mesenchyme. Messenger RNA of SMAA was initially detected in the E13.5 bladders in the peripheral mesenchyme and remained expressed in the peripheral mesenchyme in both the E15 and E16 bladders (Mann-Whitney test, $p<0.001$ ) (Fig. 3). In contrast, SMAA and SM-MHC mRNAs were undetectable in the submucosal. SM-MHC was detectable slightly later in gestation in the peripheral mesenchyme than SMAA. SMAA was also detectable in the loosely organized intermediate mesenchymal layer $\left(\mathrm{a}_{2}\right)$ between the smooth muscle and subepithelial layer of $\mathrm{E} 15-\mathrm{E} 16$ (Fig. 3).

\section{Downstream genes of sonic hedgehog (Shh) signaling path- way}

At E12.5, Patched1 (Ptc1), Gli1, and bone morphogenetic protein (Bmp4) mRNAs were expressed many folds higher in the

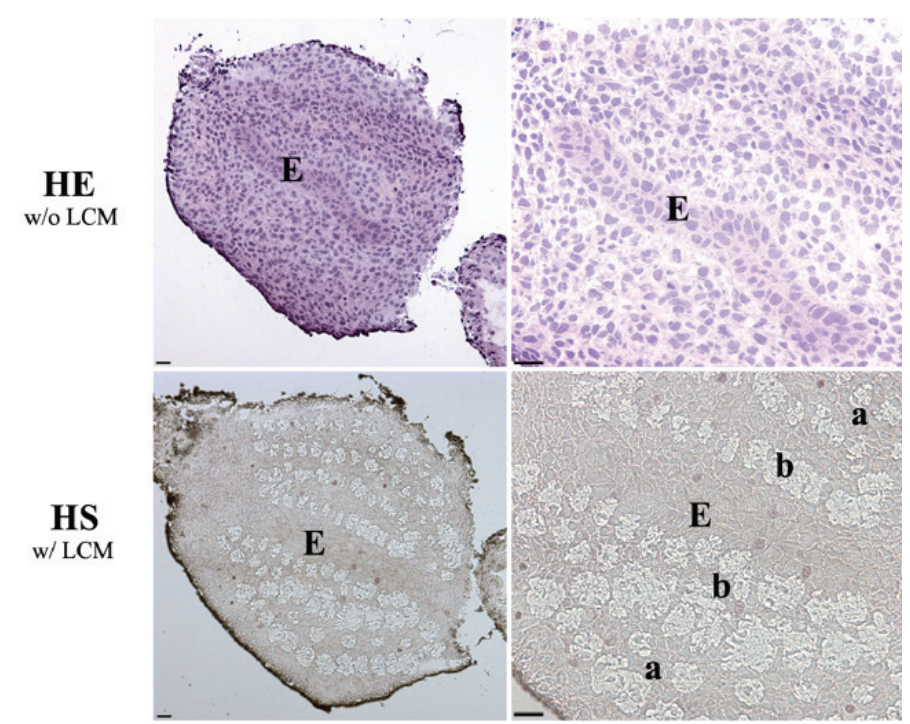

submucosa mesenchymal cells immediately adjacent to the epithelium relative to that in the peripheral serosal mesenchymal layer (Fig. 4). Ptc1 and Bmp4 genes decreased significantly in all mesenchymal layers in the E13.5 bladder (Mann-Whitney test, $p<0.001)$. Ptc1 remained low in the serosal and intermediate zones (a1, a2) in the E15 and E16 bladder mesenchyme (MannWhitney test, $p<0.001)$. In contrast, the level of-Bmp4 mRNA increased in the E15 and E16 bladders. Gli1 gene was expressed at high levels in the submucosa at E12.5 and E13.5 and decreased to low levels thereafter. At E15 the expression of Gli1 increased to a higher level in the smooth muscle layer (Mann-Whitney test, $p<0.001$ ) (Fig. 4). Gli1 increased steadily in the peripheral mesenchyme and the smooth muscle layer from E12.5 to E15 and decreased thereafter.

\section{Expression of the TGF- $\beta 1$ gene}

TGF- $\beta 1$ was minimally expressed in E12.5 bladder mesenchyme. At E13.5 TGF- $\beta 1$ increased dramatically in the serosal mesenchymal layer and then decreased in all mesenchymal compartments in the E15 and E16 bladders (Mann-Whitney test, $p<0.001$ ) (Fig. 5).

\section{Expression of serum response factor (SRF)}

Messenger RNA expression of $S R F$ was significantly upregulated in smooth muscle cells at E15 by real time RT-PCR analysis compared to other mesenchymal components in E12.5, $\mathrm{E} 13.5$, and E16 (Mann-Whitney test, $p<0.001$ ) (Fig. 6).

Meanwhile, bladder developmental illustrations with HE staining were shown with locations of $a_{1}, a_{2}$ and $b$ nomenclatures in Fig. 6.

A summary of the expression patterns of $S M A A, S M-M H C$, Ptc1, Gli1, Bmp4, TGF- $\beta$ 1, and SRF is shown in Table 2.

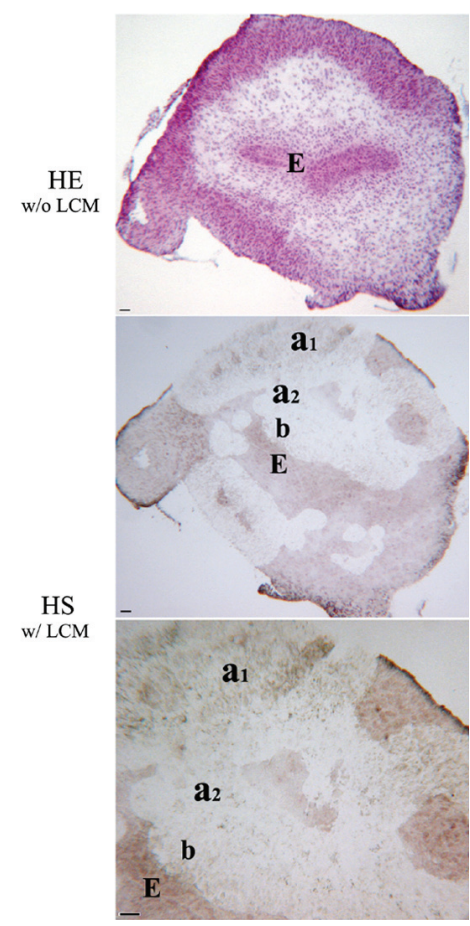

Fig. 1. (Left) Laser-assisted microdissection of mesenchyme in the E13.5 mouse bladder. (HE w/o LCM) Morphology of HE staining on serial section for laser capture microdissection. (HS w/ LCM) Morphology of HS staining after laser capture microdissection. Mesenchymal locations were chosen either immediately adjacent to the urothelium in the prospective submucosa or next to the serosal layer in the peripheral bladder mesenchyme, an area of future smooth muscle differentiation in E12.5 and E13.5 bladders. $a$, serosal zone; $b$, submucosal zone; E, epithelium. Scale bar, 50 $\mu \mathrm{m}$.

Fig. 2. (Right) Laser-assisted microdissection of mesenchyme in the E15 mouse bladder. (HE w/o LCM) Morphology of HE staining on serial section for laser capture microdissection. (HS w/

LCM) Morphology of HS staining after laser capture microdissection. Bladder mesenchymes were captured in the submucosa and in the area of peripheral smooth muscle in E15 and E16. $a_{1}$, Smooth muscle layer. $a_{2}$, intermediate zone; $b$, submucosal zone; E, epithelium. Scale bar, $50 \mu$ m. 


\section{Discussion}

Smooth muscle differentiation in the murine bladder is initiated at 13.5 days gestation under the influence of bladder urothelium (Li et al., 2006; Shiroyanagi et al., 2007). It has been proposed that the urothelial factor responsible for smooth muscle induction is sonic hedgehog (Shh) ( $\mathrm{Yu}$ et al., 2002; Shiroyanagi et al., 2007). Shh in turns acts through its receptor Ptc1 and a number of down stream mesenchymal genes such as Gli1, Bmp4, TGF$\beta 1$, and $S R F$ to both inhibit and induce smooth muscle as judged by SMAA and SM-MHC expression (Liu et al., 2000; Yu et al., 2002; Li et al., 2006; Shiroyanagi et al., 2007). Herein, we have mapped the temporal and spatial location of these genes during bladder development.

The Shh signaling pathway functions throughout development. Shh is involved in the determination of cell fate and embryonic patterning during early vertebrate development. Later during organogenesis, Shh is involved in the formation and differentiation of a variety of tissues and organs (Chuang and Kornberg, 2000). In bladder development, Ptc1, the receptor for Shh, was expressed in the mesenchyme adjacent to the bladder epithelium before the initiation of smooth muscle differentiation at E12.5, and to a far lesser extent in the prospective and definitive SMAA-producing cells later in development. The expression patterns of Ptc1 and Gli1 in the bladder are similar to that in ureteral development, since both of these genes were expressed at high levels in the mesenchymal cells immediately adjacent to the epithelium and to a lesser extent in the peripheral mesenchyme about to undergo smooth muscle differentiation. Subsequently both Ptc1 and Gli1 decreased in all mesenchymal cells after smooth muscle differentiation (Yu et al., 2002).

Bone morphogenetic protein 4 (Bmp4) has been shown to promote smooth muscle differentiation in the ureter (Raatikainen-Ahokas et al., 2000). Bmp4, a member of the transforming growth factor-beta (TGF- $\beta$ ) family, is a downstream gene of Shh pathway, and regulates several developmental processes during animal development (Raatikainen-Ahokas etal., cosal zone.
2000; Bragg et al., 2001; Sadlon et al., 2004; Shiroyanagi et al., 2007). We found Bmp4 gene expresses initially at high level in submucosa layer in E12.5 bladder (as Ptc1 gene), it is rather strong in intermediate connective tissue in E15, and later both in connective tissue and smooth muscle cell. Our results are consistent with Bmp4 inhibiting smooth muscle formation in the submucosa adjacent to the urothelium and initiating smooth muscle formation in the periphery of the bladder. It also further suggests that a similar Shh- and Bmp4-dependent pathway involves in bladder mesenchyme for smooth muscle differentiation as in ureter (Mendelsohn, 2006).

In the mouse 10T1/2 multipotent mesenchymal cell line, TGF$\beta 1$ stimulates cell growth with the up-regulation of several smooth muscle cell differentiation markers, such as SMAA, SM-MHC, smooth muscle protein 22- $\alpha$ (SM22 $\alpha$ ), and calponin (Lien et al.,
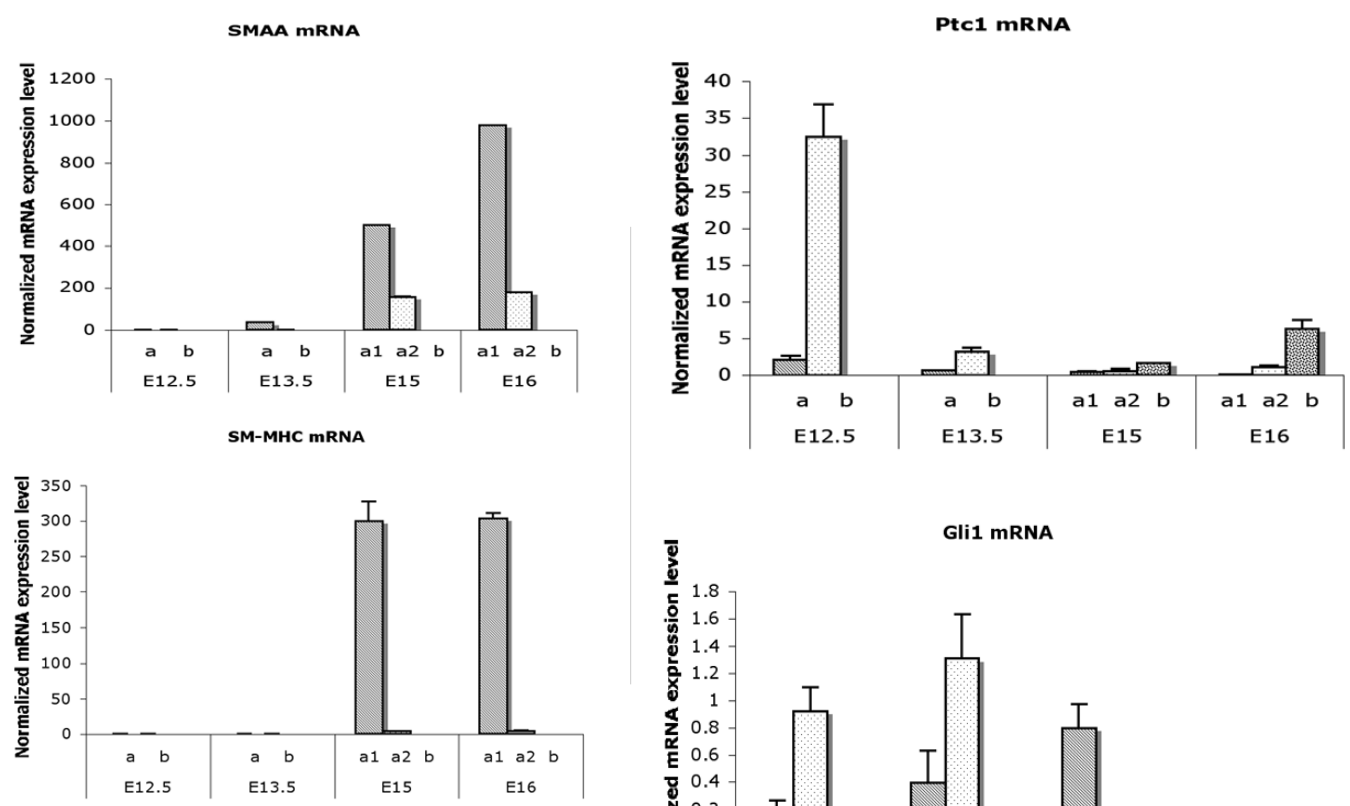

Fig. 3. (Left) Real time RT-PCR analysis of mRNA encoding SMAA and SM-MHC in laser captured mesenchymal components from each gestational stage. Expression of SMAA mRNA was detectable in the peripheral cellular population at E13.5 and increased to significantly high levels in smooth muscle cells at E15 and E16. SM-MHC was detectable temporal slightly later than SMAA and increasing in expression at E15 and E16 (MannWhitney test, $\mathrm{p}<0.001)$. a, serosal zone. $a_{1}$, smooth muscle layer; $a_{2}$, intermediate zone; $b$, submu-

Fig. 4. (Right) Real time RT-PCR analysis of mRNA encoding Ptc1, Gli1 and Bmp4 in laser
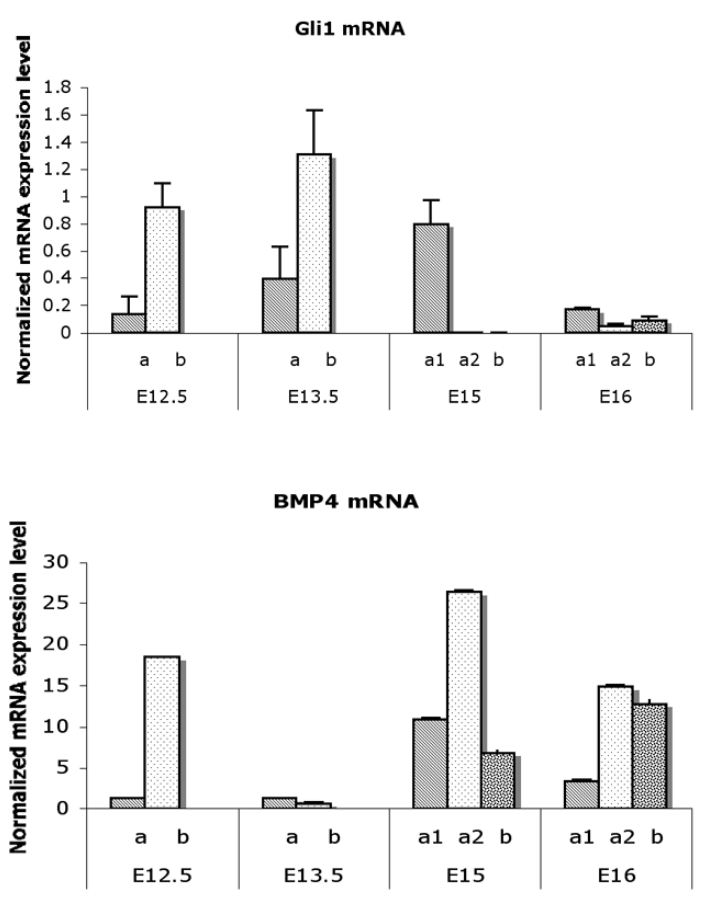
captured mesenchymal components from each

gestational stage. Expression of Ptc1, Gli1 and Bmp4 was restricted to a thin layer of mesenchymal cells in the submucosa immediately adjacent to the epithelium. Expression of both Ptc1 and Bmp4 genes was significantly decreased in all mesenchymal cells in the E13.5 bladder. Ptc1 remained at a low level in contrast to Bmp4 whose expression was increased at E15 and E16. Gli1 gene expression was up regulated in the submucosa at E13.5. At E15 the expression changed to the smooth muscle layer (Mann-Whitney test, $\mathrm{p}<0.001)$. a, serosal zone; $a_{1}$, smooth muscle layer; $a_{2}$, intermediate zone; $b$, submucosal zone. 
TABLE 1

\section{PRIMER SEQUENCES FOR TARGET GENES}

\begin{tabular}{llc} 
Genes & Primers Sequences (5'-3') & Production (bp) \\
\hline SMAA & F: ATTGTGCTGGACTCTGGAGATGGT & 187 \\
& R: TGATGTCACGGACAATCTCACGCT & \\
SM-MHC & F: TGA GCT CAG TGA CAA GGT CCA CAA & 109 \\
& R: GGA AGC CAC ATC TTT GGC CAG TTT & \\
Ptc1 & F: TGGCCCATGCATTCAGTGAAACAG & 147 \\
& R: TAGGGATCAATGCGGCCATGAAGA & \\
Gli1 & F: ACAAGTGCACGTTTGAAGGCTGTC & 116 \\
& R: GCTGCAACCTTCTTGCTCACACAT & \\
Bmp4 & F: CGTTACCTCAAGGGAGTGGA & 116 \\
& R: ATGCTTGGGACTACGTTTGG & \\
TGF- $\beta 1$ & F: GTG CGG CAG CTG TAC ATT GAC TTT & 127 \\
& R: TGT ACT GTG TGT CCA GGC TCC AAA & \\
SRF & F: TCAATGCCTTCTCTCAGGCACCAT & 151 \\
& R: ATCACAGCCATCTGGTGAAGCTGA & \\
GapDH & F: TGT GAT GGG TGT GAA CCA CGA GAA & 130 \\
& R: GAG CCC TTC CAC AAT GCC AAA GTT
\end{tabular}

F: forward, R: reverse

TABLE 2

SMOOTH MUSCLE DEVELOPMENT RELATED GENE EXPRESSION PROFILES IN THE MOUSE EMBRYONIC BLADDER MESENCHYME

\begin{tabular}{|c|c|c|c|c|c|}
\hline $\begin{array}{l}\text { Bladder } \\
\text { mesenchyme }\end{array}$ & E12.5 & E13.5 & $\begin{array}{l}\text { > smooth muscle } \\
\text { differentiation < }\end{array}$ & E15 & E16 \\
\hline \multirow[t]{2}{*}{ Peripheral (Layer a) } & \multirow[t]{2}{*}{-} & \multirow[t]{2}{*}{$\begin{array}{l}\text { SMAA } \\
\text { TGF- } \beta 1 \\
\text { Gli1 }\end{array}$} & $\begin{array}{l}\text { Smooth muscle } \\
\text { layer (layer a1) }\end{array}$ & $\begin{array}{l}\text { SMAA } \\
\text { SM-MHC } \\
\text { Gli1 } \\
\text { Bmp4 } \\
\text { SRF } \\
\text { TGF- } \beta 1\end{array}$ & $\begin{array}{l}\text { SMAA } \\
\text { Bmp4 }\end{array}$ \\
\hline & & & $\begin{array}{l}\text { Loosely organized } \\
\text { layer (Layer a2) }\end{array}$ & $\begin{array}{l}\text { SMAA } \\
\text { Bmp4 }\end{array}$ & $\begin{array}{l}\text { SMAA } \\
\text { Bmp4 }\end{array}$ \\
\hline Submucosa (layer b) & $\begin{array}{l}\text { Ptc1 } \\
\text { Gli1 } \\
\text { Bmp4 }\end{array}$ & Gli1 & & $\begin{array}{l}\text { TGF- } \beta 1 \\
\text { Bmp4 }\end{array}$ & $\begin{array}{l}\text { Ptc1 } \\
\text { Bmp4 }\end{array}$ \\
\hline
\end{tabular}

2006). Our data are consistent with these studies in that TGF- $\beta 1$ was dramatically up-regulated in the smooth muscle forming cells in the E13.5 bladder suggesting that $T G F-\beta 1$ in outer layer cells of bladder mesenchyme promotes bladder smooth muscle differentiation. Previous studies discovered that TGF- $\beta$ 's are mediated by SMAD2 and SMAD3, while BMPs are mediated by SMAD1, SMAD5 and SMAD9 (Moustakas, 2002). BMP and Activin membrane bound inhibitor (BAMBI) has a similar extracellular domain as type I receptors. It serves as a negative regulator of TGF- $\beta$ signaling and may limit TGF- $\beta$ expression during embryogenesis. The present research shows TGF- $\beta 1$ expression as a peak (especially in outer layer bladder mesenchyme at E13.5) rather for short period compared with Bmp4. This finding suggests that TGF/Bmp signaling plays corresponding role during process of bladder smooth muscle differentiation and development.

Extensive studies have established the central role of serum response factor (SRF) in controlling smooth muscle cell specific gene expression. The SMAA gene is known be regulated the transcriptional level through the binding of SRF in vascular smooth muscle (Lien et al., 2006). We have found that the SRF expression pattern directly precedes SMAA expression and that SRF localizes to the peripheral bladder mesenchyme 24 hours prior to smooth muscle differentiation (Li et al., 2006). A similar finding was also reported in gizzard smooth muscle development in which increased expression of SRF immediately preceded

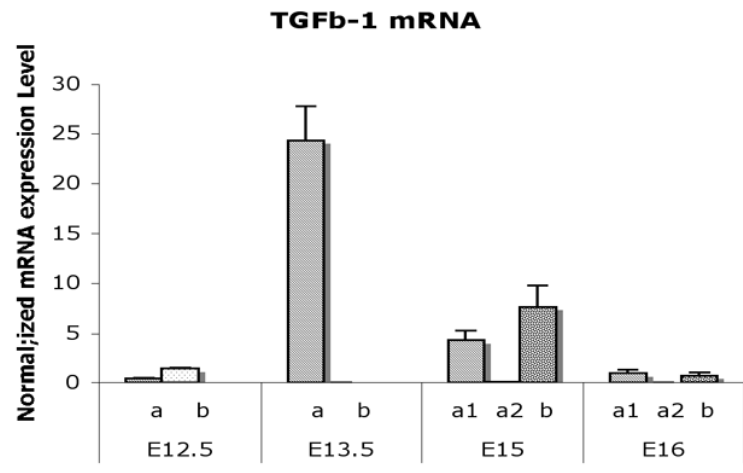

Fig. 5. Real time RT-PCR analysis of mRNA expression encoding TGF- $\beta 1$ in laser captured mesenchymal components of each gestational stage. TGF- $\beta 1$ expression was minimal in the E12.5 bladder mesenchyme. TGF- $\beta 1$ increased to the highest level in the smooth muscle differentiation layer adjacent to the serosa at E13.5 and then decreased in all mesenchymal compartments in the E15 and E16 (Mann Whitney test, $\mathrm{p}<0.001)$. Abbreviations: a, serosal zone; $a_{1}$, smooth muscle layer; $a_{2}$ intermediate zone; $b$, submucosal zone.

SMGA expression (Browning et al., 1998). SRF activates genes involved in smooth muscle differentiation and proliferation by recruiting muscle-restricted cofactors, such as the transcriptional coactivator myocardin, GATA-6, and complex factors of the ETSdomain family, respectively (Wang et al., 2002; Kanematsu et al., 2007). In the present study, expression of $S R F$ was significantly up regulated in smooth muscle cells in the E15 bladder after smooth muscle formation at E 13.5 implying that SRF plays its regulatory role as secondary factor as opposed to an initiator of smooth muscle differentiation.

Interestingly, SMAA gene was also detectable in the loosely organized mesenchymal cells between smooth muscle layer and subepithelial layer both in the E15 and E16 bladders. One

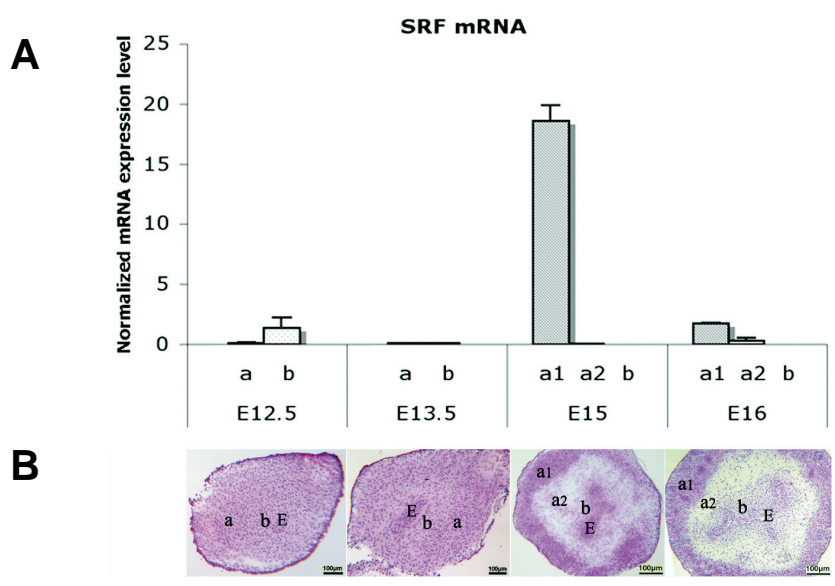

Fig. 6. Real time RT-PCR analysis of mRNA encoding SRF in laser captured mesenchymal components from each gestational stage. (A) SRF expression was significantly upregulated in smooth muscle cells at E15 compared to other mesenchymal components at E12.5, E13.5, and E16 (Mann-Whitney test, $p<0.001$ ). (B) Mouse bladder developmental illustrations with HE staining showing locations of $a_{1}, a_{2}$ and $b$ nomenclatures. Abbreviations: a, serosal zone; $a_{1}$, smooth muscle layer; $a_{2}$, intermediate zone; $b$, submucosal zone; $E$, bladder epithelium. Scale bar, $100 \mu \mathrm{m}$. 
possibility is that these cells may be smooth muscle progenitor cells at early stages of bladder smooth muscle differentiation.

In summary, the current study has generated a "snapshot view" of gene expression during bladder smooth muscle differentiation. The expression profiles of these genes provide a necessary framework for interpreting the signaling pathway that drives bladder smooth muscle formation.

\section{Materials and Methods}

\section{Animal}

FVB mice were purchased from Charles River Laboratories (Wilmington, MA) and housed in separate animal cages $(20 \xi 25 \xi 47 \mathrm{~cm})$ with laboratory-grade pine shavings (heat-treated to remove resins) as bedding. They were acclimated to $68 \sim 74^{\circ} \mathrm{F}$ and $40 \% \sim 50 \%$ relative humidity on a reversed light schedule (14 hrs light and $10 \mathrm{hrs}$ dark) and received ad libitum mouse chow and water. Timed mating was set up according experiment schedule. Noon on the day of the vaginal plug was designated as embryonic day 0.5. All animal-related procedures described here were approved by the laboratory animal resource center at University of California, San Francisco.

\section{Laser capture microdissection (LCM)}

Embryonic mouse bladders were collected at E12.5, 13.5, 15, and E16, respectively. The embryonic bladders were cut into $7 \mu \mathrm{m}$ sections and stained using Histogene ${ }^{T M}$ (HS) solution (Arcturus Engineering Inc., Mountain View, CA).

Laser capture microdissection was used to localize specific compartments of the bladder mesenchyme in relationship to the urothelium. Each sample was cryosectioned consecutively. Mesenchymal locations were chosen either next to the serosal layer or next to the urothelium in the E12.5 and E 13.5 bladders before smooth muscle differentiation (Fig. 1). In the $\mathrm{E} 15$ and $\mathrm{E} 16$ bladders, in which smooth muscle differentiation has already occurred, three locations were captured: the smooth muscle layer, the subepithelial layer, and the loosely organized mesenchymal cell layer between (Fig. 2). 50 100 cells were microdissected from each compartment of bladder mesenchyme to assure sufficient RNA. Each sample from each mesenchymal location at the same gestational stage was pooled from three fetuses from different dams.

For mesenchyme microdissection, slides were immediately transferred to a PixCell ${ }^{\circledR}$ II laser capture microscope (Arcturus). This technique employs low-power infrared laser to melt a thermoplastic film over the cells of interest, to which the cells become attached. Pictures of samples were taken using HITACHI KP-D580 high sensitivity autogain thermoelectrically cooled digital signal processor color CCD camera.

Cell clusters were transferred to caps with the thermoplastic polymer film by laser hits. Each cap was placed in an ExtracSure ${ }^{\mathrm{TM}}$ device (Arcturus), and RNA extraction was performed with the PicoPure ${ }^{\mathrm{TM}}$ RNA Isolation Kit (Arcturus). Two rounds of linear RNA amplifications were performed with RiboAmp ${ }^{\mathrm{TM}}$ RNA Amplification Kit (Arcturus) according to the manufacturer's protocol.

\section{Real-time RT-PCR}

To compare the expression levels of mRNAs within the bladder mesenchyme in respect to location relative to the urothelium, SYBR Green real-time RT-PCR technique and data analysis were performed using 96-well microwell plates and an ABI PRISM 7300 sequence detector (Applied BioSystems, Foster City, CA). Nanodrop spectrophotometer (NanoDrop Technologies, Wilmington, DE) quantification was performed as an accurate measure of the amount of intact starting RNA.

All primers for real-time PCR were designed according target gene sequences published on PubMed and synthesized by Integrated Device Technology, Inc. (San Jose, CA) (Table 1). The reaction was run online at $50^{\circ} \mathrm{C}$ for $2 \mathrm{~min}$ and $95^{\circ} \mathrm{C}$ for $10 \mathrm{~min}$, followed by 40 cycles at $95^{\circ} \mathrm{C}$ for
$15 \mathrm{~s}$ and $55^{\circ} \mathrm{C}$ for $30 \mathrm{~s}$ and an extension phase of 1 cycle at $95^{\circ} \mathrm{C}$ for 60 $\mathrm{s}, 60^{\circ} \mathrm{C}$ for $60 \mathrm{~s}$, and $95^{\circ} \mathrm{C}$ for $60 \mathrm{~s}$ (ramp time, $19.59 \mathrm{~min}$ ). All PCRs were performed in triplicate.

The housekeeping gene GapDH was amplified as a reference for the amount loaded and the quality of the cDNA. The specificity of the reaction is given by the detection of the Tms of the amplification products immediately after the last reaction cycle. Results were analyzed with the melting curve analysis software (Dissociation Curve 1.0) provided with the ABI PRISM 7300 sequence detector.

\section{Statistical analysis}

To determine the significance of differential expression in the laser captured cells, a two-sided Mann-Whitney U nonparametric analysis was performed, for which a $p$-value of $<0.05$ was considered significant.

\section{Acknowledgements}

We gratefully acknowledge many discussions with Joseph Pham and the cooperation of Lia Banie. This study was supported by the NIH grant DK073449 (to Dr. Baskin LS) and California Urology Foundation Award P0009249 (to Dr. Liu B).

\section{References}

AIRIK, R., BUSSEN, M., SINGH, M.K., PETRY, M.and KISPERT, A. (2006). Tbx18 regulates the development of the ureteral mesenchyme. J Clin Invest 116: 663674.

BASKIN, L. S., HAYWARD, S.W., YOUNG, P. and Cunha, G.R. (1996). Role of mesenchymal-epithelial interactions in normal bladder development. $J$ Urol 156: $1820-1827$

BONNER, R.F., EMMERT-BUCK, M., COLE, K., POHIDA, T., CHUAGUI, R., GOLDSTEIN, S. and LITTOA, L.A. (1997). Laser capture microdissection: molecular analysis of tissue. Science 278: 1481-1483.

BRAGG, A. D., MOSES, H.L. and SERRA, R. (2001). Signaling to the epithelium is not sufficient to mediate all of the effects of transforming growth factor beta and bone morphogenetic protein 4 on murine embryonic lung development. Mech Dev 109: 13-26.

BROWNING, C.L., CULBERSON, D.E., ARAGON, I.V., FILLMORE, R.A., CROISSANT, J.D., SCHWARTZ, R.J., and ZiIMMER, W.E. (1998). The developmentally regulated expression of serum response factor plays a key role in the control of smooth muscle-specific genes. Dev Biol 194: 18-37.

CHUANG, P.T. and KORNBERG, T.B. (2000). On the range of Hedgehog signaling. Curr Opin Genet Dev 10: 515-522.

GREEN, A.R., EDWARDS, R.E., and GREAVES, P., and WHITE, I.N. (2003). Comparison of the effect of oestradiol, tamoxifen and raloxifene on nerve growth factor-alpha expression in specific neonatal mouse uterine cell types using laser capture microdissection. J Mol Endocrinol 30: 1-11.

HARAGUCHI, R., MOTOYAMA, J., SASAKI, H., SATOH, Y., MIYAGAWA, S. NAKAGATA, N., MOON, A., and YAMADA G. (2007). Molecular analysis of coordinated bladder and urogenital organ formation by Hedgehog signaling. Development 134: 525-533.

HONG, S.H., NAH, H.Y., LEE, J.Y., GYE, M.C., KIM, C.H., and KIM, M.K. (2004) Analysis of estrogen-regulated genes in mouse uterus using cDNA microarray and laser capture microdissection. J Endocrinol 181: 157-167.

JACQUET, R., HILLYER, J., and Landis WJ. (2005). Analysis of connective tissues by laser capture microdissection and reverse transcriptase-polymerase chain reaction. Anal Biochem 337: 22-34.

JENKINS, D., WINYARD, P.J., and WOOLF, A.S. (2007). Immunohistochemical analysis of Sonic hedgehog signalling in normal human urinary tract development. J Ana 211:620-629.

KANEMATSU, A., RAMACHANDRAN, A., and ADAM, R.M. (2007) GATA-6 mediates human bladder smooth muscle differentiation: involvement of a nove enhancer element in regulating alpha-smooth muscle actin gene expression. Am J Physiol Cell Physiol 293: C1093-C1102.

KERMAN, I.A., BUCK, B.J., EVANS, S.J., AKIL, H., and WATSON S.J. (2006) Combining laser capture microdissection with quantitative real-time PCR: 
effects of tissue manipulation on RNA quality and gene expression. $J$ Neurosci Methods 153: 71-85.

KUMAR, M.S. and OWNES, G.K. (2003). Combinatorial control of smooth musclespecific gene expression. Arterioscler Thromb Vasc Biol 23: 737-747.

LI, J., SHIROYANAGI, Y., LIN, G., HAQQ, C., LIN, C.S., LUE, T.F., WILLINGHAM, E., BASKIN, L.S. (2006). Serum response factor, its cofactors, and epithelialmesenchymal signaling in urinary bladder smooth muscle formation. Differentiation 74: 30-39.

LIEN, S.C., USAMI, S., CHIEN, S., and CHIU, J.J. (2006). Phosphatidylinositol 3kinase/Akt pathway is involved in transforming growth factor-beta1-induced phenotypic modulation of $10 \mathrm{~T} 1 / 2$ cells to smooth muscle cells. Cellular Signalling 18: 1270-1278.

LIU, W., LI,. Y., CUNHA, S., HAYWARD, G., and BASKIN, L. (2000). Diffusable growth factors induce bladder smooth muscle differentiation. In vitro Cell Dev Biol Anim 36: 476-484.

MENDELSOHN, C. (2006) Going in circles: conserved mechanisms control radial patterning in the urinary and digestive tracts. J Clin Invest 116: 635-637.

MORROW, D., SWEENEY, C., BIRNEY, Y.A., GUHA, S., COLLINS, N., CUMMINS, P.M., MURPHY, R., WALLS, D., REDMOND, E.M., and CAHILL, P.A. (2007). Biomechanical regulation of hedgehog signaling in vascular smooth muscle cells in vitro and in vivo. Am J Physiol Cell Physiol 292: C488-C496.

MOUSTAKAS, A. (2002) Smad signalling network. J Cell Sci. 115: 3355-3356.

OWNES, G.K., KUMAR, M.S., and WAMHOFF, B.R. (2004). Molecular Regulation of Vascular Smooth Muscle Cell Differentiation in Development and Disease. Physiol Rev 84: 767-801.

RAATIKAINEN-AHOKAS, A., HYTONEN, M., TENHUNEN, A., SAINIO, K., and SARIOLA, H. (2000). BMP-4 affects the differentiation of metanephric mesen- chyme and reveals an early anterior-posterior axis of the embryonic kidney. Dev Dyn 217: 146-158.

SADLON, T.J., LEWIS, I., and D'ANDREA, R.J. (2004). BMP4: its role in development of the hematopoietic system and potential as a hematopoietic growth factor. Stem Cells 22: 457-474.

SHIROYANAGI, Y., LIU, B., CAO, M., AGRAS, K., LI, J., HSIEH, M.H., WILLINGHAM, E., and BASKIN, L.S. (2007). Urothelial sonic hedgehog signaling plays an important role in bladder smooth muscle formation. Differentiation 75: 968-977.

WANG, D.Z., LI, S., HOCKEMEYER, D., SUTHERLAND, L., WANG, Z., SCHRATT, G., RICHARDSON, J.A., NORDHEIM, A., and OLSON, E.N. (2002). Potentiation of serum response factor activity by a family of myocardin-related transcription factors. Proc Natl Acad Sci USA 99: 14855-14860.

WEAVER, M., BATTS, L., and HOGAN, B.L. (2003). Tissue interactions pattern the mesenchyme of the embryonic mouse lung. Dev Biol 258: 169-184.

WHITE, A.C., XU, J., YIN, Y., SMITH, C., SCHMID, G., and ORNITZ, D.M. (2006) FGF9 and SHH signaling coordinate lung growth and development through regulation of distinct mesenchymal domains. Development 133: 1507-1517.

WIJGERDE, M., McMAHON, J.A., RULE, M., and McMahon, A.P. (2002). A direct requirement for Hedgehog signaling for normal specification of all ventral progenitor domains in the presumptive mammalian spinal cord. Genes Dev 16 : 2849-2864.

YU, J., CARROLL, T.J., and McMAHON, A.P. (2002). Sonic hedgehog regulates proliferation and differentiation of mesenchymal cells in the mouse metanephric kidney. Development 129: 5301-5312.

YUCEL, S., LIU, W., CORDERO, D., DONJACOUR, A., CUNHA, G., and BASKIN L.S. (2004). Anatomical studies of the fibroblast growth factor-10 mutant, Sonic Hedge Hog mutant and androgen receptor mutant mouse genital tubercle. Adv Exp Med Biol 545: 123-148.

\section{Further Related Reading, published previously in the Int. J. Dev. Biol.}

See our recent Special Issue Developmental Morphodynamics, edited by Lev Beloussov and Richard Gordon at:

http://www.ijdb.ehu.es/web/contents.php?vol=50\&issue=2-3

Expression and comparative genomics of two serum response factor genes in zebrafish

Jody L. Davis, Xiaochun Long, Mary A. Georger, lan C. Scott, Adam Rich and Joseph M. Miano

Int. J. Dev. Biol. (2008) 52: 389-396

Rapid disappearance of the medial epithelial seam during palatal fusion occurs by multifocal breakdown that is preceded by expression of alpha smooth muscle actin in the epithelium

J R Gibbins, S Brent, M Srivastava, N Garibotto, Y M Tazawa, A Cameron and N Hunter Int. J. Dev. Biol. (2000) 44: 223-231

Role of platelet-derived growth factors in mouse development

C Betsholtz

Int. J. Dev. Biol. (1995) 39: 817-825

5 yr ISI Impact Factor $(2008)=3.271$

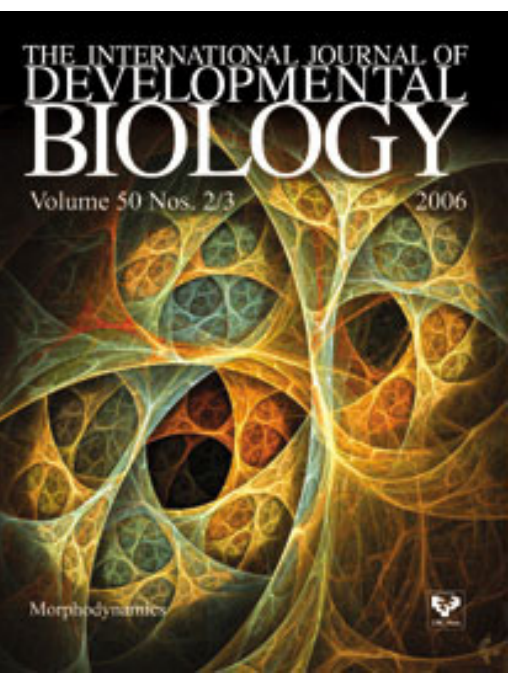

